\title{
Habit or addiction: the critical tension in deciding who should enforce hospital smoke-free policies
}

\author{
Sharon Lawn MSW PhD
}

See related research article by Schultz and colleagues on page E1334 and at www.cmaj.ca/lookup/doi/10.1503/cmaj.110235

$\mathrm{T}$ obacco use is the single most preventable cause of disease, disability and death. ${ }^{1,2,3}$ Most recently, the US Surgeon General has affirmed that there is no safe level of exposure to environmental tobacco smoke. ${ }^{1}$ The adverse affects of smoking and exposure to tobacco smoke on health pervade multiple areas of life. For these reasons, many countries have introduced smoke-free policies in a variety of community, workplace and service settings. Hospitals, in particular, are a focus of smokefree policy because their primary goal is to promote health by attending to acute health crises or serious exacerbations of chronic conditions, many of which have direct or indirect links to smoking.

Hospital staff see people with smoking-related diseases every day. In a study of health care use by 20831 employees of a large company, the American Cancer Society found that employees who smoked had more admissions to hospital (124 per 1000 v. 76 per 1000), had a longer average length of stay in hospital (6.47 v. $5.03 \mathrm{~d})$, and made six more visits to health care facilities per year than employees who did not smoke. ${ }^{4}$

Smoking-related diseases account for a high proportion of admissions to hospital and deaths across the population. ${ }^{5}$ The effectiveness of smokefree policies in reducing admissions to hospital and deaths from smoking has been supported ${ }^{6}$ and questioned, ${ }^{7}$ but hospitals play only a limited role in the journey to ill health a person takes as a result of smoking, and such reports may underestimate the range of measures needed to address the harms of smoking in the general population.

As evidence of the harms of smoking mounts, hospital administrators have clear responsibilities to provide an environment that does not undermine the health of patients and employees, and clinical staff have a clear mandate to address smoking and its affects with their patients.

These tasks are far from straightforward; they involve substantial structural, practical and cultural change. Knowing what is good for us and changing our unhealthy behaviour, or convincing others to do so, are two quite different things for patients and employees. The paper by Schultz and colleagues ${ }^{8}$ provides a rich description of the complexity of attempts to address smoking cessation and to enforce smoke-free policies in two large Canadian general hospitals. Central to the authors' findings is a description of how staff act, or fail to act, when patients' nicotine dependence is viewed as a habit rather than as an addiction, and the adverse consequences this perception has for the success of smoke-free policies. Schultz and colleagues ${ }^{8}$ provide us with a unique look at how hospital staff attempt to navigate the ethical, legal, moral and clinical debates over smoking and the enforcement of smoke-free policies on hospital grounds. The comments made by staff, although sometimes alarming, capture the tension between their opinions as public citizens, shaped by the policies and social norms of their society, and their knowledge as clinicians demanding a response (or not) to the clear evidence of the harms of smoking to the health of their patients.

Perhaps something can be learned from the many studies of smoking and smoke-free policies applied to a particularly vulnerable population - people with mental illness. Such studies lay bare the values, attitudes and contradictions that often underpin how patients and staff behave toward each other in psychiatric settings regarding the issue of smoking. In such settings, we have the privilege of seeing many of the same attitudes, behaviours and challenges described by Schultz and colleagues ${ }^{8}$ in their starkest view -

\section{- KeY POINTS}

- To more effectively address smoking and enforce smoke-free policies in hospitals, nicotine dependence should be acknowledged as an addiction and not considered a social habit.

- Clinical staff need to embed the management of nicotine dependence in routine care.

- Managing nicotine dependence in hospitals is part of a continuum of care and cannot occur in isolation from the community and context in which people live. 
honest and unambiguous. In a survey of staff at a psychiatric inpatient facility in the United Kingdom, Stubbs and colleagues ${ }^{9}$ found that almost all of the employees (93\%) thought that the mental health of patients would deteriorate if they were not permitted to have cigarettes, despite the staff also fully acknowledging the disproportionately high physical and social harms of smoking for this population of patients. In an American study at a Veterans' Affairs psychiatric hospital, staff identified many barriers to the effective enforcement of smoke-free policies, including staff resistance, lack of knowledge and time, lack of training in smoking cessation and lack of management support. ${ }^{10}$ A systematic review of studies examining the effectiveness of smokefree policies in psychiatric settings found that many of the staff's concerns about patient aggression, increased risk of fire, patients discharging themselves against medical advice and increased use of seclusion were unfounded. ${ }^{11}$ More recently, a national survey of smoke-free policy in Australia involving phone interviews with clinical staff across 99 psychiatric inpatient units highlighted the importance of staff training and support, effective leadership, lowering the rate of smoking among staff and the consistency of the staff's approach to the success of smoke-free policies. ${ }^{12}$

A central theme in all of these studies, regardless of the population involved, is the issue of responsibility. Schultz and colleagues show how the notion of responsibility can become distorted when smoking is viewed as a morally interpreted behaviour - a lifestyle choice - rather than an addiction that requires clinical support. ${ }^{8}$ Very few staff felt that enforcing the smoke-free policy was their responsibility. Fundamental to this viewpoint was the stark contrast between their perceptions and those of their patients as to whether smoking is a choice (a view held predominantly by staff) or an addiction (a view held predominantly by patients). This mismatch appears to have dire consequences for the support of smoking cessation and the enforcement of smoke-free policies.

Using examples of tobacco-related conversations between patients and staff, Schultz and colleagues clearly show that patients seek support from staff, but staff are unable to provide it in any systematic way. ${ }^{8}$ In addition, policies in the broader community and concerns about the harms of smoking appear to have little influence over the actions of many of the staff in the hospitals studied. ${ }^{8}$ This finding is important, because the change in attitude that is necessary for smoke-free policies to be effective must extend beyond the hospital door. Not only should staff model a positive clinical culture by abstaining from smoking, they should acknowledge that smoking is an addiction and have the knowledge and skills to support patients with smoking cessation and tobacco dependence as part of their clinical practice. Hospital staff need to see themselves as a necessary component of a larger set of supports for smoking cessation across the continuum of care.

\section{References}

1. How tobacco smoke causes disease: the biology and behavioral basis for smoking-attributable disease: a report of the surgeon general. Atlanta (GA): US Department of Health and Human Services, Centers for Disease Control and Prevention, National Center for Chronic Disease Prevention and Health Promotion, Office on Smoking and Health; 2010. Available: www.cdc.gov/tobacco /data_statistics/sgr/2010/index.htm (accessed 2011 Sept. 19).

2. World Health Organization. WHO report on the global tobacco epidemic: Implementing smoke-free environments. Geneva (Switzerland): The Organization; 2008. Available: www.who.int /tobacco/mpower/en/index.html (accessed 2011 Sept. 19).

3. The health consequences of smoking: a report of the surgeon general. Atlanta (GA): US Department of Health and Human Services, Centers for Disease Control and Prevention, National Center for Chronic Disease Prevention and Health Promotion, Office on Smoking and Health; 2004

4. The cost of smoking to business. American Cancer Society; 2000.

5. Smoking-attributable mortality, years of potential life lost, and productivity losses - United States, 2000-2004. MMWR Morb Mort Weekly Rep 2008;57:1226-8.

6. Shetty KD, DeLeire T, White C, et al. Changes in US hospitalization and mortality rates following smoking bans. Cambridge (MA): National Bureau of Economic Research; 2009. Available: www.nber.org/papers/w14790 (accessed 2011 Sept. 19).

7. Naiman A, Glazier RH, Moineddin R. Association of antismoking legislation with rates of hospital admission for cardiovascular and respiratory conditions. CMAJ 2010;182:761-7.

8. Schultz ASH, Finegan B, Nyiforuk CIJ, et al. A qualitative investiation of smoke-free policies on hospital property. CMAJ 2011; 183:2105.

9. Stubbs J, Haw C, Garner L. Survey of staff attitudes to smoking in a large psychiatric hospital. Psychiatr Bulletin 2004;28:204-7.

10. Essenmacher C, Karvonene-Guterrez C, Lynch-Sauer J, et al. Staff's attitudes toward the delivery of tobacco cessation services in a primary psychiatric veterans' affairs hospital. Arch Psychiatr Nurs 2009;23:231-42.

11. Lawn S, Pols RG. Smoking bans in psychiatric inpatient settings? A review of the research. Aust N Z J Psychiatry 2005;39:866-85.

12. Lawn S, Campion J. Factors associated with success of smoke-free initiatives in Australian psychiatric inpatient units. Psychiatr Serv 2010;61:300-5.

Affiliation: Sharon Lawn is with the Department of Psychiatry, Flinders University, Margaret Tobin Centre, Bedford Park, South Australia. 